Artigo Original

\title{
Classificação da participação de crianças em ocupaçóes nos contextos escolares na perspectiva da terapia ocupacional ${ }^{1}$
}

\section{Classifying children's participation in occupations in school contexts from the occupational therapy perspective}

\author{
Débora Ribeiro da Silva Campos Folha ${ }^{a}$ (D), Patrícia Carla de Souza Della Barbab ${ }^{\mathrm{b}}$ \\ ${ }^{a}$ Universidade do Estado do Pará - UEPA, Belém, PA, Brasil.

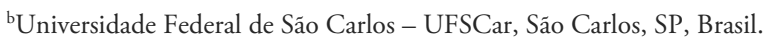

Como citar: Folha, D. R. S. C., \& Barba, P. C. S. D. (2022). Classificação da participação de crianças em ocupaçôes nos contextos escolares na perspectiva da terapia ocupacional. Cadernos Brasileiros de Terapia Ocupacional, 30, e2907. https://doi.org/10.1590/2526-8910.ctoAO21962907

\begin{abstract}
$\underline{\text { Resumo }}$
A Educação Infantil é caracterizada por ocupaçôes relacionadas ao brincar, ao autocuidado e à aprendizagem. Para a terapia ocupacional, a participação nessas ocupaçóes reflete no desenvolvimento físico, cognitivo, social, afetivo e ocupacional das crianças. Este estudo objetivou analisar formas de participação infantil em ocupaçóes nos contextos escolares e propor critérios para classificaçáo dessa participaçáo, na perspectiva da terapia ocupacional. Foi realizada uma pesquisa qualitativa, de observação participante a partir da técnica das Descriçóes Narrativas. Participaram deste estudo quatro crianças com desenvolvimento típico (DT) e quatro crianças que faziam parte do Público-Alvo da Educação Especial (PAEE), sendo uma com deficiência física e três com Transtorno do Espectro Autista (TEA). Para a análise dos dados, a técnica de Análise do Conteúdo fez emergir quatro formas de participação, a partir de elementos como envolvimento na ocupação, assistência necessária ou autonomia na participação, tolerância, interaçôes sociais, motivação e iniciativa. Essas formas de participação foram denominadas de participaçáo plena, participação ativa assistida, participação rudimentar e participação restrita. A participação plena foi preponderante manifestada pelas crianças DT e a participação ativa assistida esteve relacionada à criança PAEE com deficiência física. Já a participação rudimentar e a participação restrita foram evidenciadas exclusivamente por crianças PAEE com TEA. Consideram-se os resultados relevantes para a identificação precoce de facilitadores e barreiras para a participação, bem como para o adequado provimento de condições e intervençôes que potencializem a participação
\end{abstract}

\footnotetext{
${ }^{1}$ Este artigo compóe a Tese de Doutorado "Perspectiva ocupacional da participação de crianças na educação infantil e implicaçōes para a Terapia Ocupacional”, do Programa de Pós-Graduação em Terapia Ocupacional (PPGTO/DTO/UFSCar).
} 
de todas as crianças nos ambientes escolares e para o fortalecimento e ampliação da atuação dos terapeutas ocupacionais nestes.

Palavras-chave: Terapia Ocupacional, Criança, Educação Infantil, Avaliação do Desenvolvimento Neuropsicológico, Participação Social, Atividades Cotidianas.

\begin{abstract}
$\underline{\text { Abstract }}$
Early childhood education is characterized by occupations related to playing, self-care and learning. For occupational therapy, the participation in these occupations reflects on the physical, cognitive, social, affective and occupational development of children. This study aimed to analyze forms of child participation in occupations in school contexts and to propose criteria for classifying this participation, from the perspective of occupational therapy. A qualitative research was carried out, with participant observation using the technique of Narrative Descriptions. Four children with typical development (TD) and four children who were part of the Target Audience Students of Special Education (TSSE) participated in this study, one with physical disability and three with Autism Spectrum Disorder (ASD). For data analysis, the Content Analysis technique revealed four forms of participation, based on elements such as: involvement in the occupation, necessary assistance or autonomy in participation, tolerance, social interactions, motivation and initiative. These forms of participation were called full participation, assisted active participation, rudimentary participation and restricted participation. Full participation was preponderantly manifested by TD children and assisted active participation was manifested by TSSE children with physical disabilities. Rudimentary participation and restricted participation were evidenced exclusively by TSSE children with ASD. The results are considered relevant for the early identification of facilitators and barriers to participation, as well as for the adequate provision of conditions and interventions that enhance the participation of all children in school environments and for the strengthening and expansion of the work of occupational therapists in these scenarios.
\end{abstract}

Keywords: Occupational Therapy, Child, Child Rearing, Developmental Neuropsychological Assessment, Social Participation, Activities of Daily Living.

\title{
Introduçáo
}

As ocupações infantis são compreendidas como açóes intencionais que as crianças realizam ao longo de seu desenvolvimento (Folha \& Della Barba, 2020; Abjornslett et al., 2015). Ao realizarem ocupaçóes com a família, amigos ou outras pessoas, as crianças iniciam a constituição de um repertório ocupacional que permitirá desenvolverem papéis diversos, enquanto criança que brinca, que estuda, que se se relaciona com outras pessoas e que cuida de si mesma (Mandich \& Rodger, 2006).

Terapeutas ocupacionais são profissionais que consideram, em suas práticas, a interação das pessoas com os ambientes que frequentam e com as ocupaçóes nas quais se envolvem. Com base nisso, podem pensar intervençóes que habilitem essas pessoas para o desempenho de ocupaçóes que elas querem fazer, precisam fazer ou que a comunidade em geral espera que elas façam.

Dentre as ocupaçóes frequentemente realizadas pelas crianças, este estudo destaca as relacionadas aos contextos escolares. A Resolução n ${ }^{\circ}$ 500/2018 do Conselho Federal de Fisioterapia e Terapia Ocupacional (COFFITO), reconhece o terapeuta ocupacional 
enquanto profissional apto para atuar na educação regular e/ou especial na perspectiva inclusiva, em salas de recursos multifuncionais, e em outros contextos educacionais formais e não formais em todas as modalidades, etapas e níveis de ensino (Brasil, 2018).

$\mathrm{O}$ ambiente da escola se apresenta, nesse sentido, como um contexto no qual as crianças realizam ocupaçôes diversas. No cotidiano das práticas de Educação Infantil, as crianças desenvolvem ocupaçóes voltadas para o brincar, para o autocuidado e para a aprendizagem de conteúdos escolares (Gartland, 2001; Mulligan, 2012). Considera-se que a participação nessas ocupaçóes contribui para o desenvolvimento físico, cognitivo, social, afetivo e ocupacional da criança (Mandich \& Rodger, 2006). Pensando em identificar e analisar a participação de crianças com e sem deficiência nas ocupaçóes relacionadas aos contextos escolares, esse estudo discute elementos que permitem classificar a participação infantil neste contexto.

A participação nas ocupaçôes infantis na escola e na comunidade é essencial para o seu crescimento e desenvolvimento, visto que é por meio delas que as crianças desenvolvem habilidades, envolvem-se em ocupaçóes e situações compartilhadas com outras pessoas, aprendem a se expressar, constroem significados, aprendem a desempenhar o papel ocupacional de estudante e desenvolvem aspectos relacionados ao brincar e às relaçóes interpessoais (Law et al., 2006; Ziviani \& Muhlenhaupt, 2006).

Assim, os contextos escolares se encontram estruturados em torno de ocupaçóes diversas, que podem constituir as denominadas ocupações escolares. Os autores que têm realizado esta discussão sob a perspectiva ocupacional costumam abordar esse conceito a partir dos tipos ou das próprias ocupaçóes realizadas nos contextos escolares, a saber: brincar, autocuidado e aprendizagem formal (Gartland, 2001; Ziviani \& Muhlenhaupt, 2006; Mulligan, 2012). Neste estudo, as ocupaçóes escolares são compreendidas como:

[...] ocupaçôes que compõem o cotidiano educacional e que, ao mesmo tempo em que promovem o aprendizado, a socialização e o desenvolvimento por meio da participação nelas, requerem essa participaçáo para promover o aprendizado, a socialização e, por conseguinte, o desenvolvimento ocupacional dos estudantes (Folha, 2019, p. 180).

Estudos brasileiros já vêm se debruçando a estudar a participação infantil na escola. Dentre os eixos estudados com frequência, tem-se: a análise ambiental e suas implicaçóes para o desenvolvimento das crianças que frequentam creches, considerando-a um ambiente de proteção ao desenvolvimento infantil (Jurdi et al., 2017; Joaquim \& Rizzo, 2018); contribuições da terapia ocupacional para promover a inclusão de crianças com Transtornos do Espectro Autista (TEA) (Della Barba \& Minatel, 2013), Paralisia Cerebral (PC) (Rocha \& Deliberato, 2012) e Transtorno do Déficit de Atenção e Hiperatividade (TDAH) (Silva et al., 2012), entre outros públicos-alvo, referindo resultados consonantes e relacionados ao aumento da participação infantil nas atividades educacionais e no fomento de diálogos com professores, para que estes desenvolvam atividades adaptadas para as necessidades dos alunos; percepçóes de professores e familiares sobre a participação de crianças com deficiência física na escola (Oliveira et al., 2015; Zafani et al., 2016), açóes de terapia ocupacional para a formação de professores com vistas à efetivação da educação inclusiva (Martinez et al., 2016; Folha \& Carvalho, 2017).

Além disso, pesquisas sobre intervenções de terapia ocupacional na escola têm sido observadas com duas ênfases principais: no desempenho escolar e na reabilitação, tendo a 
escola como lócus de observação e intervenção, mas enfocando o desempenho funcional. Alguns estudos relacionam funcionalidade ao desempenho escolar (Pelosi \& Nunes, 2011; Della Barba \& Minatel, 2013); outros enfatizam prioritariamente aspectos ligados à funcionalidade e desempenho ocupacional (Carrasco, 2005; Moreira et al., 2014).

Essas intervençóes nos espaços das escolas, embora demonstrem um forte viés clínicoreabilitativo, colaboram para a ampliação dos campos de prática dos terapeutas ocupacionais. Contudo, muitas vezes, não alcançam a discussão sobre a participação infantil na escola, por se debruçarem ao estudo de habilidades específicas e/ou do desenvolvimento neuropsicomotor, sem contemplar as crianças como seres ocupacionais.

Este estudo é fundamentado na perspectiva ocupacional, caracterizada por compreender os seres humanos como seres ocupacionais, ou seja, pessoas que estáo constantemente envolvidas em ocupaçôes que passam a compor os seus cotidianos. Além disso, é baseada na crença de que as pessoas possuem uma necessidade intrínseca de realizarem ocupaçóes que sejam significativas em seu contexto cultural e socioeconômico.

Essa participação em ocupaçóes ocorre independentemente da faixa etária e repercute no desempenho e no desenvolvimento humano. Nessa perspectiva, as pessoas também influenciam e são influenciadas pelas ocupaçóes que compóem seu dia-a-dia, tais como as relacionadas ao autocuidado, à participação social, à educação, ao trabalho ou ao lazer (Mandich \& Rodger, 2006).

Acerca do conceito de participação adotado, Law et al. (2006) concebem que, segundo a definição literal, o termo significa "fazer parte". Em uma perspectiva ocupacional, a participação é tanto processo quanto resultado da interação entre as pessoas e os ambientes que frequentam. Essas autoras consideram que há elementos que interferem diretamente na participação, como as habilidades motoras, sociais, comunicativas e a cognição, além dos ambientes e pessoas que convivem com as crianças.

Assim, este estudo objetivou analisar formas de participação infantil em ocupaçóes nos contextos escolares e propor critérios para classificação dessa participação, na perspectiva da terapia ocupacional.

\section{Método}

Tratou-se de um estudo de abordagem qualitativa, que corresponde à recorte de Tese de Doutorado desenvolvida no âmbito de um Programa e Pós-Graduação de uma Universidade Pública no interior do Estado de São Paulo.

\section{Local e participantes}

A coleta de dados foi realizada em quatro Unidades de Educação Infantil (UEI) vinculadas à Secretaria Municipal de Educação (SEMEC) do município de Belém (PA), no período de junho de 2017 a janeiro de $2018^{2}$.

A amostra desta pesquisa foi constituída por: crianças público-alvo da Educação Especial (PAEE), regularmente matriculadas em UEI da SEMEC de Belém (PA), uma por UEI; e crianças de 4 e 5 anos, com desenvolvimento típico, regularmente matriculadas em

\footnotetext{
${ }^{2} \mathrm{O}$ projeto de pesquisa ao qual este estudo é vinculado foi aprovado por um Comitê de Ética em Pesquisa (CEP) com seres humanos do Centro de Ciências Biológicas e da Saúde (CCBS) da Universidade do Estado do Pará (UEPA), sob o parecer n 1.855.178. Após aprovação do CEP, o Termo de Consentimento Livre e Esclarecido (TCLE) foi assinado pelos responsáveis das crianças participantes.
} 
UEI da SEMEC de Belém (PA), da mesma turma da criança PAEE selecionada em cada UEI, conforme apresentado no Tabela 1:

Tabela 1. Caracterização das crianças participantes da pesquisa.

\begin{tabular}{cccccc}
\hline \multicolumn{2}{c}{ Crianças $^{1}$} & Idade & Gênero & Uei & Impressáo diagnóstica \\
\hline \multirow{2}{*}{$\begin{array}{c}\text { Crianças } \\
\text { PAEE }^{2}\end{array}$} & MG & 5 anos & Masculino & A & $\begin{array}{c}\text { Má formaçáo congênita do Membro Superior } \\
\text { Direito (MSD) }\end{array}$ \\
\cline { 2 - 6 } & F & 5 anos & Masculino & B & Transtorno do Espectro Autista \\
& AM & 4 anos & Masculino & C & Transtorno do Espectro Autista \\
\hline \multirow{2}{*}{$\begin{array}{c}\text { Crianças } \\
\text { DT }^{3}\end{array}$} & IL & 5 anos & Feminino & D & Transtorno do Espectro Autista \\
& PV & 5 anos & Masculino & A & Desenvolvimento típico \\
& CE & 5 anos & Masculino & B & Desenvolvimento típico \\
\hline & J & 5 anos & Masculino & C & Desenvolvimento típico \\
\hline
\end{tabular}

Fonte: Elaboração própria (2020). ${ }^{1}$ Nomeadas da partir das iniciais de seus nomes, a fim de zelar pela privacidade dos participantes do estudo. ${ }^{2}$ Crianças Público-Alvo da Educação Especial, conforme a Política Nacional de Educação Especial na Perspectiva da Educação Inclusiva. ${ }^{3}$ Crianças com Desenvolvimento típico.

Foram incluídas, neste estudo, crianças com desenvolvimento típico e crianças PAEE; que tivessem entre 4 e 5 anos; que fossem regularmente matriculadas e assíduas na etapa educacional da Educação Infantil na Rede Municipal de Ensino; que apresentassem laudo ${ }^{3}$, no caso das crianças PAEE; e cujos responsáveis legais concordassem com a observação da criança, registrando seu aceite por meio da assinatura do Termo de Consentimento Livre e Esclarecido para pais (TCLE). Foram excluídas crianças que não atendessem aos critérios de inclusão supramencionados ou tivessem comorbidades como mais de uma deficiência apresentada.

\section{Coleta de dados}

Foi utilizada a observação participante como técnica de imersão em campo para coleta de dados. A exigência de rigor para uma observaçáo criteriosa nos levou a adotar o método de Descrição Narrativa (Bentzen, 2012) para a apreensão dos dados ligados aos comportamentos infantis. Este método consiste no registro, de forma contínua e em detalhes, do que a criança faz e diz, por si só e em interação com outras pessoas, ambientes ou objetos. O objetivo principal do registro narrativo é obter uma análise detalhada e objetiva de comportamento sem inferências, interpretaçóes ou avaliaçóes. Nesse método, o vídeo ou áudio gravado (e sua posterior transcriçáo) pode ser usado sozinho ou em combinaçáo com notas escritas para registrar uma análise permanente do comportamento da criança.

A descrição narrativa preconiza que os registros devem preservar descriçóes de comportamentos, sequências cronológicas e contextos, tendo como benefícios no contexto da Educaçáo Infantil: a) Ausência de seletividade; b) Fornecimento de um relato completo do que ocorreu durante o tempo que esteve no fluxo de comportamento de uma criança; c) Compreensão do contexto (cenário e situação), junto do comportamento; d) Entendimento

\footnotetext{
${ }^{3}$ Apesar de se concordar que o laudo médico não deve ser exigência para que as crianças possam usufruir dos serviços do Atendimento Educacional Especializado (AEE), optou-se por adotar este critério de inclusão para garantir, para fins de credibilidade científica, de que haveria representantes do PAEE envolvidos nesta pesquisa.
} 
dos comportamentos com base nas situaçóes vivenciadas; e e) Captação de todos os comportamentos e contextos sob condiçóes naturalistas (Bentzen, 2012).

A coleta de dados deste estudo ocorreu no período de Junho de 2017 a Janeiro de 2018, de segunda à sexta, no turno da manhã em três UEI e no turno da tarde em uma UEI. O horário de coleta pela manhã era de 7:30h às 11:30h; pela tarde, era de 14:00h às 17:30h. A observação era registrada em áudio, utilizando gravador de voz, e eram também realizadas anotaçóes escritas em momentos nos quais a gravação do áudio fosse interferir no desenvolvimento das atividades escolares pela turma observada.

Esta fase contou com a participação da pesquisadora principal e mais três auxiliares de pesquisa, que receberam formação pela pesquisadora para a utilizaçáo do método de descrição narrativa em três encontros de formaçáo sobre o método. Esses encontros envolveram o treino individual e coletivo para utilização do método, a fim de favorecer a padronização da observação e dos registros, entre todas as observadoras, garantindo a apreensão de informaçóes o mais detalhadas possível acerca da realidade observada. Ao longo do período de coleta de dados, foram também realizados supervisão e acompanhamento periódico destes auxiliares de pesquisa pela pesquisadora principal.

\section{Análise dos dados}

Para a sistematização e análise do material de investigação, foi utilizado o método de análise temática do conteúdo (Bardin, 2011), que envolveu três etapas básicas: a préanálise, a descrição analítica e a interpretação inferencial.

$\mathrm{Na}$ pré-análise, as descriçóes narrativas foram organizadas, processo no qual os dados coletados em áudio foram transcritos e os dados coletados em notas escritas foram organizados, juntos, em arquivos do Word for Windows, por criança e em ordem cronológica. Este movimento produziu um relato de descrição narrativa de cada criança participante da pesquisa. Esta etapa foi realizada pela pesquisadora principal e pelas três auxiliares de pesquisa.

$\mathrm{Na}$ etapa de descrição analítica, foi realizada a leitura em profundidade das descriçōes narrativas, identificando temas, ocupaçóes, comportamentos e demais elementos que se apresentavam e se repetiam sobre cada criança. Esse movimento deu início à codificação, classificação e categorizaçáo de ocupaçóes, rotinas, ambientes, comportamentos observados e formas de participação manifestadas pelas crianças, compondo quadros de referências capazes de aglutinar os resultados do estudo. Esta etapa foi realizada pela pesquisadora principal e supervisionada pela orientadora da pesquisa, que cumpriu o papel de profissional especialista para julgamento da pertinência das categorias que emergiram da análise.

Já a interpretação inferencial consistiu no aprofundamento da análise dos dados derivados da fase anterior, identificando os conteúdos trazidos em cada categoria e conduzindo o pesquisador para o estabelecimento de relaçóes entre a problemática pesquisada e o objeto do estudo. Este recorte de pesquisa traz resultados sobre os conteúdos relacionados à participação infantil e os discute à luz de referenciais teóricos pertinentes.

\section{Resultados e Discussáo}

Esta seção reúne os resultados de pesquisa que permitem compreender e analisar como crianças com Desenvolvimento Típico (DT) e crianças Público-Alvo da Educação Especial (PAEE) participam das ocupaçóes relacionadas à Educação Infantil. Do mesmo modo, pretende 
integrar a discussão destes resultados, contribuindo para constituição deste campo que ainda se encontra sob construção teórica: o campo da terapia ocupacional em contextos escolares.

No contexto da infância, a participação pode ser compreendida como o produto do progresso das transaçóes entre a criança, o ambiente e suas ocupaçóes (Law et al., 2006; Ziviani \& Muhlenhaupt, 2006). A perspectiva ocupacional pode favorecer a percepçáo de diferentes formas de participaçáo. Permite reconhecer elementos que caracterizam essa noção de fazer parte, como a interação social e o interesse, a iniciativa e a motivação para o engajamento em uma ocupação. Assim, possibilita identificar como cada pessoa participa de determinado ambiente.

As definiçóes correntes de participação enfatizam o significado (meaning), expandindo a definição literal para compreender a participação como a partilha, o envolvimento, o ser ativo ou a experimentação de algo (Law et al., 2006; Chien \& Brown, 2017; Lane, 2012). É válido ressaltar que este estudo não se propôs a explorar o meaning, por este termo ter uma dimensão subjetiva que não pode ser apreendida apenas pela observaçáo, exigindo que seja autorrelatada por quem desenvolve a participaçáo. Como a faixa etária dos participantes desta pesquisa foi de 4 a 5 anos, optou-se por não envolver esta dimensão, diante da dificuldade metodológica de apreender autorrelatos de crianças tão pequenas.

É válido ponderar que este estudo também não teve como objetivo avaliar, mensurar ou comparar a participação das crianças com desenvolvimento típico e atípico, mas sim conhecer as diferentes formas de participação e caracterizá-las, em um viés compreensivo, a partir da vivência de imersão no cotidiano da Educação Infantil.

Pontes et al. (2018) destacam o conceito de padrão de atividade, caracterizado pelo desempenho regular ou repetido, individual ou coletivo, de grupos de atividades conectadas por características semelhantes e/ou conforme estabelecido socialmente.

A leitura dos dados de pesquisa, por meio da técnica de Análise do Conteúdo (Bardin, 2011), fez emergir quatro categorias temáticas, capazes de configurar alguns padrôes de atividade, enquanto perfis de participação identificado na pesquisa, descrito no Tabela 2 , a seguir:

Tabela 2. Classificação da participaçáo de crianças nas ocupaçóes em contextos escolares.

\begin{tabular}{cl}
\hline Tipo de participaçáo & \multicolumn{1}{c}{ Definiçáo } \\
\hline Participaçáo plena & $\begin{array}{l}\text { Participação autônoma, minimamente supervisionada, na qual as crianças expressam domínio } \\
\text { da sequência necessária para o cumprimento das tarefas, compreensão e obediência a comandos, } \\
\text { motivação, criatividade, iniciativa e destreza na realização das ocupaçóes }\end{array}$ \\
\hline \multirow{2}{*}{ Participaçáo ativa assistida } & $\begin{array}{l}\text { Participação em consolidação, ativa, com motivação e iniciativa, moderadamente supervisionada } \\
\text { e em um ritmo próprio, adaptada e flexível, conforme as necessidades da criança }\end{array}$ \\
\hline Participaçáo rudimentar & $\begin{array}{l}\text { Participaçáo rudimentar e permanentemente supervisionada que, embora envolva motivação, } \\
\text { envolve um repertório ocupacional limitado, empobrecido, de imitação ou repetitivo, ou, ainda, } \\
\text { quando a criança náo expressa completa compreensão e atendimento a comandos ou inicia a } \\
\text { participação, mas a interrompe antes do alcance do propósito da atividade }\end{array}$ \\
\hline Participaçáo restrita & $\begin{array}{l}\text { Participação marcada pela supervisão com frequente assistência e intervenção permanente e } \\
\text { direta da professora (ou da estagiária) ou ainda pela dependência e/ou pela náo realização da } \\
\text { atividade }\end{array}$ \\
\hline
\end{tabular}

Fonte: Elaboração própria (2020).

Conforme os resultados apresentados, constatou-se que a participação plena foi observada enquanto característica da participação de crianças DT. A participação ativa assistida se mostrou, predominantemente, como característica da criança PAEE com 
deficiência física. Já a participação rudimentar e a participação restrita foram características exclusivas de crianças PAEE com TEA.

A apresentação dos resultados e discussão deste estudo estão organizadas a partir dos três eixos estruturantes da Educação Infantil: autocuidado, brincar e aprendizagem formal.

A participação das crianças nas atividades de autocuidado foi observada em variados ambientes: na sala de aula, durante as atividades de despir, vestir, enxugar-se, pentear os cabelos, gerenciar material de uso pessoal, tirar e calçar sapatos e sandálias; no refeitório, durante as atividades de alimentação nos lanches, almoço e jantar; e no banheiro, durante o banho, o uso do sanitário, a lavagem das mãos e a escovaçáo dos dentes.

As ocupaçóes relacionadas ao autocuidado são conceituadas como as tarefas básicas de cuidado de si - como alimentaçáo, uso do banheiro e vestir -, também denominadas, na terapia ocupacional, de Atividades de Vida Diária (AVD). A respeito delas, foi possível identificar a estreita relaçáo das AVD com os contextos escolares, o que reforça o intuito de desenvolver a perspectiva ocupacional para atuação de terapeutas ocupacionais neste campo (Gartland, 2001; Mulligan, 2012).

Já o brincar, na perspectiva ocupacional adotada neste estudo, figura como a principal ocupação realizada durante a infância e corresponde tanto a um fim em si mesmo quanto a um meio para a aquisição de habilidades e para o engajamento ocupacional em outras ocupaçóes que passaráo a ser estruturantes do cotidiano infantil (Bundy, 2012; Lynch \& Moore, 2016). Além disso, a legislação educacional brasileira preconiza a transversalidade do brincar, enquanto eixo estruturante e norteador das práticas de educação infantil (Brasil, 2009).

A perspectiva de Ferland (2006) compreende o brincar enquanto uma ação subjetiva, na qual o prazer, a curiosidade, o senso de humor e a espontaneidade se encontram, caracterizando uma conduta escolhida livremente e da qual não se espera nenhum rendimento específico. Assim, o brincar envolve prazer, descoberta, domínio da realidade, criatividade e expressão. Esta autora considera que o brincar envolve diferentes componentes de desempenho, com destaque para os componentes sensoriais, motores, cognitivos, afetivos e sociais.

Também denominadas de sessão ou situação de aprendizagem, as atividades de aprendizagem de conteúdo formal dizem respeito às atividades pedagógicas que intencionam o ensino de determinado conteúdo. Foram preconizadas desde o Referencial Curricular Nacional para a Educação Infantil (RCNEI - Brasil, 1998) e ratificadas pelas Diretrizes Curriculares Nacionais para a Educação Infantil (Brasil, 2009).

Preveem a intervenção direta do professor para que as crianças tenham contato com diversos conhecimentos que sejam tanto baseados nas propostas dos professores, quanto na escuta das crianças. Essa intervenção do professor é preconizada visando à ampliação das capacidades infantis de apropriação dos conceitos, dos códigos sociais e das diferentes linguagens (Brasil, 1998).

A seguir, são discutidos os padrôes de participação a partir destes três eixos estruturantes, analisando-os a partir da perspectiva ocupacional.

\section{Participaçáo plena}

A participação das crianças DT nas ocupaçóes escolares foi denominada no âmbito de uma participação plena. 
Nas ocupações relacionadas ao autocuidado, essa participação plena, majoritariamente autônoma e minimamente supervisionada pode ser ilustrada pelos seguintes excertos das descriçóes narrativas, sobre o momento do despir:

10:01h - A professora chama as meninas para trocarem de roupa. J pega a mochila, retira a toalha e pendura a mochila de volta no espaço correspondente só de mochilas, retira a roupa, dobra-as, coloca sob a cadeira e se enrola na toalha (J, 29 de novembro de 2017).

9:56h - A professora anuncia o momento do banho. CE tira a sua roupa, camisa primeiro e short depois, e pega o seu roupão, vestindo-o. Ele veste o roupão, fechandoo, e aguarda a sua vez de ser chamado para o banho (CE, 10 de novembro de 2017).

Nos momentos de higiene, essa autonomia também foi observada, diante de uma atividade supervisionada pela professora:

10:24h - J tira a toalha e coloca sob a pia, abre a torneira do chuveiro, molha-se pulando. A professora pede para elas desligarem o chuveiro e coloca sabonete líquido na mão delas e orienta para esfregarem bem as partes do corpo, mencionando-as (axilas, virilhas e pescoço). J esfrega-se conforme os comandos, depois liga o chuveiro e se enxágua, conversando com as outras meninas. 10:33h - J desliga o chuveiro, pega a sua toalha na pia, enxuga-se (J, 29 de novembro de 2017).

O momento do vestir também foi marcado pela participaçáo plena das crianças DT, que demonstraram, além de habilidades para o vestir, capacidade e costume no gerenciamento de seus próprios pertences:

10:17h - Após o banho, a professora entrega a cueca limpa de I, ele coloca a toalha no ombro esquerdo e veste a cueca em pé, equilibrando-se, olha a peça de roupa dos dois lados e escolhe o correto para vestir. Depois se enrola na toalha. 10:27h - A professora começa a distribuir as roupas, perguntando sempre de quem é cada peça e mostrando aos alunos. I identifica as roupas dele, levanta-se, as busca com a professora $e$ as veste, sentado, conversando com um colega, com destreza e rapidez (I, 05 de fevereiro de 2018).

Durante os momentos de alimentação, a participação plena pode ser explicitada nos excertos a seguir:

10:10h - Todas as crianças estâo sentadas no refeitório, a professora distribui os pratos com comida, PV segura seu prato e o coloca sobre a mesa, pega a colher com a mão direita e come, devagar, enquanto conversa com um colega. 10:15h - A professora distribui fruta (laranja cortada ao meio), PV a pega da bandeja, coloca na boca e amassa com as duas máos, chupando. Ele enfia o dedo para puxar os caroços e volta a comer (PV, 06 de dezembro de 2017).

10:40h - A professora entrega os pratos com comida (arroz, frango desfiado e feijäo preto), I come sem conversar, observa os colegas. Pede mais frango, a professora coloca mais para ele, ele volta a comer fazendo som "bum hum hum hum" e roda o prato com 
a mão esquerda, com a colher na mão direita. Ele pinça os grãos de feijão e coloca na boca. 10:51h - I finaliza a refeição e aguarda os colegas (I, 29 de janeiro de 2018).

Estudos já realizados apontam que as aquisições de habilidades para a realização de ocupaçóes relacionadas ao autocuidado ocorrem na faixa etária de 4 e 5 anos (Mulligan, 2012; Shepherd, 2012). Esses dados corroboram com a participação plena das crianças DT participantes deste estudo e que se encontram nesta faixa etária.

É importante reconhecer a necessidade de fornecer oportunidades para que as crianças possam experimentar essa participação, de modo que crianças que náo tenham oportunidades para tal, ainda que tenham desenvolvimento típico, poderáo demonstrar outras formas de participaçáo. Assim, pode-se pensar que crianças DT tendem a ter mais oportunidades do que crianças PAEE para praticar as habilidades exigidas para o autocuidado, visto que estudos sugerem essa conduta da família e de outros cuidadores com frequência (Chapparo \& Lowe, 2012; Chapparo \& Hooper, 2005).

Quanto à participação nas ocupaçóes relacionadas ao brincar, as crianças DT também evidenciaram uma participação plena, conforme ilustram os seguintes excertos das descrições narrativas:

As crianças estão próximas da mesa, sentadas nas cadeiras ou em pé. PV está em pé, encaixando peças de montar, e refere ter montado um "carro voador", e faz movimentos de vôo com os braços. PV desmonta o carro e encaixa as peças de forma diferente, referindo construir um ônibus. Em seguida faz movimentos na mesa, deslizando o brinquedo montado (PV, 22 de novembro de 2017).

A professora organiza as crianças encostadas nas paredes para a realização de uma corrida. Ela enche balóes e os entrega para as meninas, explicando que devem andar com o baläo entre as pernas, sem deixar cair ou estourar e que se caso caisse, tinha que colocar entre as pernas novamente, para poder andar até a linha de chegada. As crianças começam a disputa, duas a duas, enquanto as outras estão sentadas no chão, de costas para a parede. As crianças torcem, gritando pelo nome dos participantes. J disputa com uma colega e ganha a corrida. Os alunos correm e a abraçam (J, 20 de novembro de 2017).

Apesar de restrita à criança $\mathrm{MG}$, também foi possível observar momentos de participaçáo plena no brincar de crianças PAEE, como exemplificam os excertos das descriçôes narrativas de $\mathrm{MG}$, a seguir:

09:44h - Brincando na área livre, $M G$ vê uma criança de outra turma com um brinquedo do dinossauro, se aproxima e pergunta se pode brincar, o menino permite, ele sorri feliz, manuseia o dinossauro, bate-o no chão, arrasta-o pela cadeira e demais espaços do parque. 09:48h - Ele pega o dinossauro, anda pelo parque, depois decide sentar mais longe, brinca sozinho com o brinquedo, aponta para as pessoas, bate no chão, caminha com o brinquedo, pega uma pétala de flor no chão e coloca na boca do dinossauro. 09:55 - Um colega se aproxima e pede para brincar com ele, ele concorda $e$ os dois brincam sentados. $M G$ arrasta o brinquedo, corre e o amassa, enquanto o colega observa, eles conversam e riem. 09:58h - MG coloca o dinossauro para escorregar sozinho, depois escorrega também. Repete várias vezes a brincadeira com o dinossauro no escorrega (MG, 13 de setembro de 2017). 
16:25h - A professora reúne pequenos grupos ao redor de cada mesa e distribui quebra cabeças sobre as mesmas. Ela orienta as crianças a montarem em equipe. Assim, grupos de 4 crianças se reúnem em torno de cada mesa. MG manuseia as peças e monta algumas. Ele usa a mão esquerda para levar a peça para o local onde ela será encaixada e usa a mão direita para amassar e, de fato, encaixá-la. Ele parece bastante envolvido na atividade, faz tentativas até conseguir encaixar as peças, nem sempre certo, mas fica entretido e parece motivado para realizar a montagem (MG, 30 de agosto de 2017).

Na terapia ocupacional, o brincar é um potencializador natural do desenvolvimento infantil. Por meio dele, a criança experimenta o prazer e a descoberta, desenvolve o domínio da realidade e a criatividade, bem como aprende a se expressar (Ferland, 2006). Algumas pesquisas, realizadas no campo da terapia ocupacional, destacam a centralidade que o brincar ocupa nas práticas de educação infantil e contribuiçóes dos terapeutas ocupacionais neste âmbito (Gartland, 2001; Graham et al., 2014). Além disso, alguns estudos já apontam benefícios da perspectiva ocupacional nesse sentido, considerando-a capaz de abordar a criança em sua integralidade, contemplando a complexidade implicada nos processos educacionais na primeira e na segunda infância (Case-Smith, 2001; Davis \& Polatajko, 2006).

Emmel et al. (2001) consideram que os adultos têm papel fundamental como mediador das brincadeiras, potencializando a relação da criança com os ambientes que frequenta. Essa mediação inclui: 1) a organização de espaços para brincadeiras e experiências das crianças, estabelecendo regras e condiçóes ao desenvolvimento das atividades; 2) O auxílio na distribuição de funçóes, permitindo que as crianças adquiram autonomia em um ambiente de segurança, confiança e afetividade; 3) $\mathrm{O}$ auxílio às crianças, mostrando-lhes como proceder por meio de gestos e instruçóes verbais em situaçóes interativas e proporcionando-lhes experiências e descobertas; 4) Estímulo à participação de todos com segurança; 5) Observação do grupo e a possibilidade de trabalhar com as dificuldades encontradas; 6) Oferta de materiais e sugestão de atividades; 7) Incentivo à organização de brincadeiras, mediando problemas que o grupo não consegue resolver sozinho.

Tanto em relação ao autocuidado quanto ao brincar, as crianças DT evidenciaram participação plena, enquanto as crianças PAEE, excetuando-se MG, variaram suas formas de participação entre as três outras categorias de participação.

Semelhantes características foram percebidas no que se refere à participação de crianças DT nas atividades de aprendizagem formal, evidenciando uma participação plena, conforme narram os excertos das descriçóes narrativas, a seguir, durante a rodinha pedagógica e as sessóes de aprendizagem:

08:53h - A professora entoa cançôes que são imediatamente acompanhadas pelas crianças. PV participa e sorri em alguns trechos das músicas, cantando junto com as crianças, prestando atenção em um mural com as imagens das cantigas impressas. Em seguida, a professora o chama para escolher uma música no painel, ele se levanta e escolhe "escravos de Jó". 08:58h - A professora e as crianças continuam cantando, dessa vez com coreografias. PV acompanha todas as músicas, sorrindo e realizando todas as coreografias (PV, 22 de novembro de 2017).

8:44h - A professora distribui papeis para as crianças e anuncia a tarefa, que era desenhar o personagem da história do dia anterior ("Coração tum-tum"). Ela também distribui giz de cera com diferentes tons de vermelho. I prende a folha na 
mesa com o antebraço esquerdo e segura o giz de cera vermelho com a mäo direita. Ele pinta devagar, primeiro pintando as bordas próximas à linha, preenchendo a figura. Depois, risca com mais força o centro, e diz que acabou. 8:58h - A professora, então, distribui quadradinhos de EVA recortados, e pinga cola no desenho, orientando as crianças a colarem na linha do contorno do coração. I segura a folha na mesa com a ponta dos dedos e realiza a colagem até sua conclusáo, aparentemente concentrado (I, 31 de janeiro de 2018).

\section{Participação ativa assistida}

Já no que se refere à maioria das crianças PAEE, a participação em atividades de autocuidado foi caracterizada de duas formas predominantes: participaçáo ativa assistida ou participaçáo restrita. A participação ativa assistida foi predominante na criança MG:

15:50h-A professora liga os chuveiros, $M G$ se molha. A professora distribui shampoo nas cabeças de todos os alunos. Ela coloca shampoo na cabeça de $M G$, orientando que se esfregue, ele obedece, usa ambos os membros superiores, as duas mãos, deliberadamente, para lavar a cabeça. A professora começa a distribuir sabonete líquido nas mãos das crianças, orientando que ensaboem seus corpos. $M G$ une as mãos para receber uma quantidade de sabonete líquido e começa a espalhá-lo pelo corpo, usando as duas mãos. Parcialmente ensaboado, a professora liga o chuveiro novamente e orienta que eles se lavem. As crianças vão finalizando seus banhos e a professora começa a distribuir as toalhas. $M G$ pega sua toalha com a mâo esquerda e começa a se enxugar. A professora o auxilia a vestir a cueca, abaixando a roupa para que ele coloque as pernas. Para as demais crianças, ela somente entregou a cueca em mãos, para que eles mesmo vestissem. Em seguida, ela o auxilia a enrolar a toalha em seu corpo para voltar à sala de aula. Os demais meninos enrolaram-se a si mesmos em suas toalhas (MG, 23 de agosto de 2017).

Como apenas a criança $\mathrm{MG}$ evidenciou participação ativa assistida nas atividades de aprendizagem formal, neste estudo, a deficiência física se desvelou como menor impeditivo para a participação de crianças na Educação Infantil, quando comparada ao TEA, a partir da participação de MG. Isto pode estar relacionado ao tipo de deficiência física apresentada pela criança participante do estudo, desvinculada de comprometimentos na mobilidade e na cogniçáo, visto que outros estudos identificaram a deficiência física como condiçáo proporcionalmente limitante para a participação de crianças nos contextos escolares (Pfeifer et al., 2011; Graham et al., 2014).

Em relação ao brincar das crianças PAEE, observou-se motivação para o envolvimento e uma participação ativa assistida em diversos momentos de brincar livre, ainda que com um repertório lúdico empobrecido ou repetitivo. Os excertos a seguir explicitam essas situaçóes:

8:00h - A professora passa nas mesas distribuindo um quebra cabeça por mesa e as crianças começam a manusear as peças para montar. 8:10h - AL se aproxima da professora, que puxa uma cadeira e coloca ao seu lado, chamando-a para se sentar. AL senta nessa cadeira. Manuseia as peças do quebra-cabeça, tenta montar, a professora a parabeniza e motiva. Ela consegue encaixar 4 peças. Vez ou outra, ela pega uma única peça e a explora com as duas mãos em frente ao rosto, braços fletidos 
e cotovelos em cima da mesa. Sustenta o interesse nessa exploração por aproximadamente 5 minutos (AL, 31 de agosto de 2017).

9:40h - A estagiária pega um jogo de boliche, com 6 pinos e uma bola e chama F para brincar com ela. Ela posiciona os pinos no chão e estende o braço com a bola para que F pegue e a jogue, derrubando os pinos. Folha para ela, pega a bola e a joga em direçâa aos pinos, mas sem derrubá-los. Ela repete 2 vezes e ele joga a bola novamente nas duas vezes. Na segunda vez ele derruba 3 dos pinos, mas em todas as vezes ele pula eufórico, sorrindo e batendo palmas sempre que arremessa a bola, ao que a estagiária comemora junto a ele (F, 21 de junho de 2017).

A necessidade de promoção da participação de crianças nas ocupações relacionadas ao brincar na escola pressupóe trabalho colaborativo dos terapeutas ocupacionais juntos aos professores no âmbito da Educação Infantil. Essa necessidade já foi identificada e contemplada por terapeutas ocupacionais em estudos anteriores (Chapparo \& Lowe, 2012; Sant'Anna, 2016).

Dentre os tipos de brincar, é possível observar que as crianças PAEE com TEA comumente expressavam participação mais efetiva em um brincar mais concreto, em detrimento do brincar simbólico. O brincar simbólico se refere à forma de brincar caracterizada pelo faz de conta e pela abstração, sinalizando habilidades cognitivas desenvolvidas e consolidadas para representar as vivências cotidianas, com imaginação e criatividade, por meio do brincar, o que pode estar também relacionado à habilidades mais complexas que ainda se encontram em desenvolvimento pelas crianças PAEE com TEA (Rutherford et al., 2007; Hobson et al., 2013; Fiaes \& Bichara, 2009). Ainda no que se refere ao brincar concreto, como os excertos de AL e F explicitam, muitas vezes, a mediaçáo do adulto é necessária para promover a participação, ainda que assistida.

Uma participação ativa assistida também foi observada nas crianças PAEE durante a realização de ocupações relacionadas à aprendizagem formal, como referido a seguir:

8:28h - A professora distribui papel e giz de cera a cada criança. AM segura imediatamente o papel quando distribuido pela professora. AM começa a pegar giz por giz e rabiscar o papel rapidamente, com força, mesmo a professora falando para pintar devagar para evitar quebrar o giz. Ele troca os giz de cera, pinta com vários, quebra alguns. A professora se aproxima, o aconselha a pintar devagar. Segura sua mão por cima do lápis e faz traçôes levemente no papel. Depois se afasta e AM continua riscando o papel com os giz de cera. Às vezes, segura um lápis em cada mão. Pinta traços em geral. As demais crianças pintam ambientes e pessoas (AM, 28 de agosto de 2017).

8:55h - As professoras da UEI se organizam para realizar atividade de pintura coletiva no quintal. A professora distribui pincéis à todas as crianças. AM pega tinta no pincel, caminha até o painel pregado na parede e faz traços com o pincel. Ele repete esse processo várias vezes, pegando cores diferentes no pincel e pintando com a mão direita. As crianças fazem círculos, rostos e outros rabiscos. AM faz traços e linhas, evidencia estar bem concentrado nesta atividade (AM, 23 de agosto de 2017).

A participação das crianças PAEE com TEA nas sessôes de aprendizagem também sugere a necessidade de um olhar ocupacional que analise o engajamento ocupacional e 
formas de promovê-lo, visando a uma participação efetiva de todas as crianças nos ambientes educacionais, assim como o alcance dos objetivos de aprendizagem.

Esse processo sugere um planejamento pedagógico efetivo para o provimento do Atendimento Educacional Especializado (AEE) na Educação Infantil (Brasil, 2015), com vistas à facilitação da participação dos alunos PAEE nas atividades educacionais. Cabe ao professor do AEE identificar as necessidades e habilidades de cada criança a partir de um estudo de caso, a fim de propor formas de eliminaçáo das barreiras existentes. De posse dessas informaçóes, este professor poderá elaborar um plano de atendimento educacional especializado/individualizado que orientará as ações de atendimento à criança. Para o desenvolvimento dessas ações, este documento prevê que o professor do AEE deve buscar o fortalecimento de uma "rede intersetorial de apoio ao desenvolvimento integral da criança" (Brasil, 2015, p. 5). O terapeuta ocupacional é profissional reconhecidamente apto para compor esta equipe de intersetorial (Brasil, 2018).

\section{Participaçáo rudimentar}

Já os tipos de participação rudimentar e restrita das crianças PAEE foram predominantemente observados nas crianças AL, F e AM e caracterizam uma participação marcada por uma intervenção permanente e direta da professora (ou da estagiária, no caso de F) ou, ainda, pela dependência.

Os excertos a seguir evidenciam a participação rudimentar constatada durante a realização de ocupaçóes relacionadas ao autocuidado:

11:00h - F anda pelo refeitório, de um lado para o outro. A estagiária o chama para lavar as mãos, na pia que há no próprio refeitório. Ele se dirige à pia e se posiciona em frente a ela, levantando os braços e colocando as mãos sob a torneira. Ela liga a torneira e ele molha as mãos. Ela espirra sabonete líquido nas mãos dele e ele as esfrega brevemente e depois deixa os braços estendidos, apoiados no balcão e aguarda ela finalizar a lavagem. Assim ela faz (F, 23 de junho de 2017).

9:45h - Após o banho, a professora conduz as crianças de volta à sala. As roupas das crianças estão sobre as mesas, na sala de aula. Quando elas retornam para a sala, a professora chama $A M$ e coloca sua fralda, enquanto ele manipula a blusa dele, que está do avesso, tentando colocar seus braços de forma descoordenada. A professora, após colocar a fralda, pega a blusa das mãos dele e entrega a bermuda a ele, fornecendo comando verbal para que ele vista. AM pega a bermuda com as duas mãos, como se a fosse vestir. Ele permanece com a roupa nas máos, enquanto a professora organiza as toalhas das crianças que já estão vestidas e o observa, dando várias vezes o comando verbal para que ele se vista. Após muita insistência da professora, ele começa a abaixar a roupa, tentando colocar uma das pernas no orifício correspondente, porém se desequilibra várias vezes e desiste. A professora se agacha ao lado dele, orientando o que ele deve fazer para se vestir e ele vai obedecendo. Ele apoia um dos braços na perna da professora e tenta colocar uma perna no short, ainda sem êxito. Ele senta no chão e, finalmente, consegue colocar uma das pernas no short, embora do lado errado. A professora, então, o ajuda, colocando a perna corretamente, no orifício correto, e ele veste o outro lado. Depois ele se levanta e fica em pé, com o short na altura do joelho, o suspende e fecha o velcro que há no lugar de um ziper. Em seguida, a professora coloca a blusa pelo orifício do pescoço e orienta que ele termine de vestir, colocando os 
braços. Ele coloca o braço esquerdo corretamente, mas coloca o braço direito no mesmo orificio do pescoço. A professora o chama e o auxilia a vestir corretamente o braço direito (AM, 17 de agosto de 2017).

Embora autores constatem que a realização de ocupações relacionadas ao autocuidado ocorre na faixa etária de 4 e 5 anos (Mulligan, 2012; Shepherd, 2012), alguns estudos enfatizam aspectos que podem influenciar nessas aquisiçóes e, consequentemente, na participação da criança, tais como a existência de deficiências, ambientes que não sejam promotores do desenvolvimento e adultos que mediam essas ocupaçóes e que as desenvolvem pelas crianças (Shepherd, 2012; Hemmingsson et al., 2003).

A participação rudimentar também foi observada nas sessões de aprendizagem:

9:00h - No momento da chamada, as crianças devem reconhecer e pegar a tarjeta com seu nome. A professora deixa na mesa o nome de AL e a chama. Aponta qual o nome que ela deve pegar, mas ela pega outro. Então, a professora diz "não, AL, o seu nome é esse". E entrega o nome correto nas mãos da criança. AL pega seu nome e encaixa no painel de chamada de modo diagonal. A professora ajusta o encaixe no painel, enquanto dizia "muito bem, AL" (AL, 20 de setembro de 2017).

8:20h - A professora distribui tarjetas com os nomes das crianças no chão, no meio do círculo no qual as crianças estão sentadas. Cada criança deve reconhecer seu nome escrito na tarjeta correspondente. Uma das crianças aponta o nome de AM mas ele não o reconhece quando chega a vez dele, um colega o reconhece e aponta a tarjeta correta, a qual ele pega (AM, 04 de setembro de 2017).

A predominância de características anteriores às esperadas para sua faixa etária (Ferland, 2006) sugere a necessidade de maiores investimentos na promoçáo de oportunidades e mediação para que estas crianças tenham uma participação efetiva, com motivação, desenvolvendo iniciativa e interaçáo social nas situaçôes de brincadeiras nos ambientes escolares. Além disso, a própria convivência e interação recíproca dessas crianças PAEE com as crianças DT nas práticas educacionais já representa possibilidades de ampliaçáo desse repertório lúdico, a partir da imitação e da assimilação de novas habilidades por meio da interação social e do brincar.

Considera-se que os resultados deste estudo apontam para uma confluência de fatores que possam ter interferido na participação das crianças PAEE, tais como: a necessidade de mediação enquanto assistência e treinamento, ao invés de realização pelo adulto enquanto cuidador; o provimento de condiçóes adaptadas para cada criança conforme suas necessidades e habilidades; e o fornecimento de condiçôes ambientais para o aprendizado e a realização das atividades de autocuidado com crescente autonomia pelas crianças PAEE.

\section{Participação restrita}

A participação restrita foi observada exclusivamente nas crianças PAEE com TEA, como exemplificam os excertos referentes às ocupaçóes de autocuidado:

10:35h-As meninas vão juntas para o banheiro, conduzidas pela professora $e$ enroladas cada uma em sua toalha. Ao chegarem ao banheiro, a professora recolhe as 
toalhas e todas vão para os chuveiros, exceto $A L$, que permanece ao lado da professora. A professora pega a ducha e chama AL para se molhar, que obedece. A professora a molha e AL sorri. A professora passa sabão no corpo de AL e fornece comando para ela ensaboar o braço e depois as pernas. Ela esfrega o sabão parcialmente. A professora ensaboa um pouco mais e depois a lava e a enxuga (AL, 05 de setembro de 2017).

7:35h - As crianças indicam que AM está defecado, a professora confere, suspendendo a blusa dele, e confirma a informação. AM parece não perceber o que está acontecendo. E somente se levanta para ir ao banheiro quando a professora o puxa suavemente pelo braço (AM, 28 de agosto de 2017).

Para Mulligan (2012), as crianças em idade pré-escolar geralmente continuam a exigir algum nível de supervisão por razóes de segurança, de supervisão ou de auxílio. Pode-se perceber que, com as crianças PAEE, essa supervisão, e muitas vezes a mediação, ocorre por questôes de necessidade de assistência.

Quando uma criança manifesta uma deficiência severa, o desempenho independente em ocupaçôes é frequentemente desafiador. Muitas delas podem ser concluídas com dispositivos adaptativos ou apenas parcialmente executadas pela criança. Nesses casos, os cuidadores (familiares ou, nesse caso, professores) necessitam de orientaçóes para que assumam o papel de mediadores durante os momentos de vestir e alimentar, por exemplo (Shepherd, 2012). Essa mediação proporcionada pelo cuidador tende a envolver a criança nas referidas ocupaçóes, fazendo com que ela se sinta partícipe da mesma.

Além do grau de severidade da deficiência, os valores familiares e os padrôes de interação também contribuem para variaçóes em relação ao nível de independência das crianças pequenas, de modo que as oportunidades de praticar habilidades de autocuidado e o reforço para tais comportamentos, como se vestir de forma independente ou gerenciar os pertences, sejam variáveis (Mulligan, 2012).

Outros excertos trazem constatações da participação restrita destas mesmas crianças em ocupaçóes relacionadas ao brincar:

8:00h - A professora orienta que cada criança pegue um brinquedo e se sente em uma das mesas para brincar com ele. Todas as crianças levantam-se e começam a caminhar em direçâo à um grande cesto de brinquedos que fica em um canto da sala. Cada uma escolhe um brinquedo e senta em uma das mesas. AM caminha junto com as crianças em direção à regiāo da sala que tem as mesas e cadeiras, sem pegar nenhum brinquedo. Ele se senta em uma cadeira encostada na parede, fora das mesas. Senta de pernas cruzadas sobre a cadeira, enquanto as crianças brincam nas mesas. Ele fica sentado, calado, sozinho, olhando para as mesas onde as crianças brincam, próximo à ele. 8:07h - AM continua olhando as crianças brincando. A professora percebe que ele está sentado sem brinquedo e o questiona: "AM, onde está o seu brinquedo?" Ele a olha e sorri, sem nada responder. Ele sentado sem brinquedo, calado, apenas olhando as crianças que brincam (AM, 17 de agosto de 2017).

10:15h - As crianças brincam sentadas nas mesas. A professora enche um balão e o entrega para AL. Ela o pega, se levanta, o manipula, o aperta, depois o larga. Depois anda e tenta sair da sala, mas a professora a chama e a distrai novamente com $o$ balão, o jogando para o alto. AL o olha e tenta alcançá-lo. Se distrai por alguns instantes, mas logo tenta sair da sala novamente. A professora a chama, fala 
novamente que "não pode", ela a olha, choraminga e vocaliza. A professora a conduz até a mesa, junto aos demais colegas, que montam quebra-cabeça. Ela se interessa inicialmente, sai do colo da professora e senta na cadeira ao lado, manuseia as peças, tenta encaixá-las, mas náo consegue montar nenhuma. A professora a auxilia. Após aproximadamente 2 minutos, AL se levanta e anda pela sala, voltando para o colo da professora, que a acolhe (AL, 24 de agosto de 2017).

Ferland (2006) descreve que há comportamentos do brincar que são observáveis em crianças em idade pré-escolar. Aproximadamente entre 18 meses e 3 anos, as crianças demonstram comportamentos de brincar relacionados à repetição, exploraçáo, imitaçáo, aquisição de sentido de propriedade, faz de conta, estar com outras crianças, iniciar o compartilhamento do brinquedo e afirmar-se enquanto pessoa em interação com o ambiente, reconhecendo-se. Já entre 3 e 6 anos, é esperado que as brincadeiras infantis envolvam as atitudes de imaginar, fantasiar-se, desenhar, socializar e colaborar.

Com base nesse referencial, observamos que a atitude lúdica de crianças PAEE com TEA evidenciou repertório lúdico pessoal restrito para o que se espera para sua faixa etária. Isto sugere que as crianças PAEE, especialmente as com TEA, necessitam de condiçóes ambientais e de mediação para a promoção de sua participação no brincar, no âmbito da Educação Infantil. Alguns destes aspectos já foram abordados por outras pesquisas no campo e sugerem resultados compatíveis com os achados deste estudo (Murdock \& Hobbs, 2011; Memari et al., 2015; Klinger \& Souza, 2015).

Também a participação restrita das crianças PAEE foi registrada durante as sessões de aprendizagem:

9:17h - A professora introduz a atividade do dia, a respeito da letra P e orienta que todas as crianças se organizem em frente à televisão para ouvirem uma música sobre a letra P. As crianças sentam e AL fica andando pela sala. 9:20h - O vídeo começa e a professora coloca uma cadeira para AL na primeira fila e a chama para sentar-se. Ela atende ao chamado e se senta, olha para a televisão. O vídeo passa uma vez. Na segunda vez, a professora o passa pausando em cada cena, para explorar as imagens e as palavras com a letra $P$. As crianças interagem verbalmente diante dos questionamentos da professora. AL olha para a televisáo, para o teto e as paredes da sala, para os colegas. Não verbaliza e nem olha para a professora enquanto ela explica, mostra os objetos com a letra P e faz os questionamentos (AL, 19 de setembro de 2017).

Esse resultado indica a necessidade de apoios, adaptaçôes e mediação por um adulto, no sentido de favorecer a participação e, consequentemente, o aprendizado. As situaçóes de mediação entre professor e aluno PAEE são fundamentais para a efetividade da participação da criança PAEE nas atividades escolares, conforme Oliveira \& Araujo (2019), que destacam exemplos de mediaçóes pedagógicas a partir de um planejamento de atividades com organização do espaço, do tempo, de materiais e, fundamentalmente, com estratégias capazes de contemplar o uso da comunicação, a fim de promover a interação.

Apesar dos dados que apontam para uma participaçáo restrita de crianças PAEE, considera-se que a crítica não deve recair sobre esse perfil de participação, menos ainda sobre os diagnósticos por elas apresentados, mas sim na necessidade de provimento de condiçóes, como estrutura, ambientes e recursos materiais e humanos para a potencialização dessa participação. 


\section{Consideraçóes Finais}

A partir do objetivo de analisar formas de participação infantil em ocupaçóes nos contextos escolares e propor critérios para classificação dessa participação, na perspectiva da terapia ocupacional, considera-se que as principais ocupaçóes realizadas na Educação Infantil foram contempladas e analisadas: o brincar (enquanto eixo transversal das práticas), o autocuidado e a aprendizagem formal.

A abordagem metodológica utilizada favoreceu este movimento, visto que a técnica das Descriçóes Narrativas proporcionou o encontro, a vivência aprofundada, o contato horizontalizado e a plena possibilidade de conhecer crianças, em toda a sua complexidade e riqueza, compreendendo o que fazem, como e quando fazem, e, muitas vezes com quem realizam estas ocupações.

A adoçáo da perspectiva ocupacional permite aos terapeutas ocupacionais enxergar oportunidades ou barreiras para a participação das crianças em ocupaçóes na Educação Infantil, contribuindo com a multiplicidade de olhares que devem ser direcionados às crianças nessa faixa etária de intenso desenvolvimento e potencialidades, apresentem elas desenvolvimento típico ou atípico. Essa perspectiva tende a contribuir para a implementação de práticas que se façam sensíveis, inclusivas e baseadas em evidências resultantes de estudos anteriores.

Considera-se que esses relevantes resultados auxiliam a traçar caminhos a fim de sensibilizar os olhares para as especificidades que perpassam pelas formas de participação infantil nas ocupaçóes em contextos escolares; de reconhecer formas de participaçáo que se mostrem, ocasionalmente, apartadas das habilidades esperadas para determinada faixa etária, valorizando as estratégias desenvolvidas e, ainda, o potencial para novas possibilidades; de identificar precocemente facilitadores e barreiras para a participação, assim como demandas para o adequado provimento de condiçóes, como estrutura, ambientes e recursos materiais e humanos, visando potencializar a participação de todas as crianças nos ambientes escolares e para o fortalecimento e ampliação da atuação dos terapeutas ocupacionais nestes.

\section{Referências}

Abjornslett, M., Engelsrud, G. H., \& Helseth, S. (2015). How children with disabilities engage in occupations during a transitional phase. Journal of Occupational Science, 22(3), 320-333. http://dx.doi.org/10.1080/14427591.2014.952365.

Bardin, L. (2011). Análise de conteúdo. São Paulo: Ediçôes 70.

Bentzen, W. R. (2012). Descrições Narrativas. In W. R. Bentzen. Guia para observação e registro do comportamento infantil (pp. 99-116). São Paulo: CENGAGE.

Brasil. (1998). Referencial curricular nacional para a educaçâo infantil. Brasília: MEC/SEF.

Brasil. (2009, 17 de dezembro). Resolução no 5, de 17 de dezembro de 2009. Fixa as Diretrizes Curriculares Nacionais para a Educação Infantil. Diário Oficial [da] República Federativa do Brasil, Brasília, seção 1, p. 18.

Brasil. (2015). Nota técnica conjunta $n^{\circ}$ 02/2015/MEC/SECADI/ DPEE - SEB/DICEI. Orientaçóes para a organização e oferta do atendimento educacional especializado na educação infantil. Brasília: MEC.

Brasil. Conselho Federal de Fisioterapia e Terapia Ocupacional - COFFITO. (2018, 26 de dezembro). Resoluçáo no 500, de 26 de dezembro de 2018. Reconhece e disciplina a especialidade de Terapia Ocupacional no Contexto Escolar, define as áreas de atuaçáo e as competências do terapeuta ocupacional especialista em Contexto Escolar e dá outras providências. Diário Oficial [da] República Federativa do Brasil, Brasília, p. 81. 
Bundy, A. (2012). Children at play: can I play, too? In S. J. Lane, \& A. C. Bundy. Kids can be kids: a childhood occupations approach (pp. 28-43). Philadelphia: F.A. Davis Company.

Carrasco, B. G. (2005). Retrato de uma creche: possibilidades da atuação da Terapia Ocupacional na educaçáo infantil (0-2 anos). Cadernos de Terapia Ocupacional da UFSCar, 13(2), 117-121.

Case-Smith, J. (2001). Development of childhood occupations. In J. C. O’Brien \& H. Kuhaneck. CaseSmith's Occupational Therapy for Children (pp. 71-94) Missouri: Mosby.

Chapparo, C., \& Hooper, E. (2005). Self-care at school: perceptions of six-year-old children. The American Journal of Occupational Therapy, 59, 67-77. http://dx.doi.org/10.5014/ajot.59.1.67.

Chapparo, C., \& Lowe, S. (2012). School: participating in more than just the classroom. In S. J. Lane, \& A. C. Bundy. Kids can be kids: a childhood occupations approach (pp. 83-100). Philadelphia: F.A. Davis Company.

Chien, C. W., \& Brown, T. (2017). Assessing children's occupations and participation. In S. Rodger \& A. Kennedy-Behr (Eds.), Occupation-centred practice with children: a practical guide for Occupational Therapists (pp. 133-163). Reino Unido: Wiley Blackwell.

Davis, J., \& Polatajko, H. (2006). Occupational development of children. In S. Rodger \& J. Ziviani (Eds.) Occupational Therapy with children: understanding children's occupations and enabling participation (pp. 136-157). Malden: Blackwell Publishing.

Della Barba, P. C. S., \& Minatel, M. (2013). Contribuiçóes da Terapia Ocupacional para a inclusão escolar de crianças com autismo. Cadernos de Terapia Ocupacional da UFSCar, 21(3), 601-608. http://dx.doi.org/10.4322/cto.2013.062.

Emmel, M. L. G., Pereira, E. C., \& Oliveira, A. A. E. (2001). Avaliação de materiais lúdicos para crianças normais e especiais: relatório final de pesquisa. São Carlos: DTO/UFSCar.

Ferland, F. (2006). O modelo lúdico: o brincar, a criança com deficiência física e a terapia ocupacional. São Paulo: Roca.

Fiaes, C. S., \& Bichara, I. D. (2009). Brincadeiras de faz-de-conta em crianças autistas: limites e possibilidades numa perspectiva evolucionista. Estudos de Psicologia, 14(3), 231-238. http://dx.doi.org/10.1590/S1413-294X2009000300007.

Folha, D. R. S. C. (2019). Perspectiva ocupacional da participação de crianças na Educação Infantil e implicaçōes para a Terapia Ocupacional (Tese de doutorado). Universidade Federal de São Carlos, São Carlos.

Folha, D. R. S. C., \& Carvalho, D. A. (2017). Terapia Ocupacional e formação continuada de professores: uma estratégia para a inclusão escolar de alunos com transtornos do neurodesenvolvimento. Revista de Terapia Ocupacional da Universidade de São Paulo, 28(3), 281-289.

Folha, D. R. S. C., \& Della Barba, P. C. S. (2020). Produção de conhecimento sobre terapia ocupacional e ocupaçóes infantis: uma revisão de literatura. Cadernos Brasileiros de Terapia Ocupacional, 28(1), 227245. http://dx.doi.org/10.4322/2526-8910.ctoar1758.

Gartland, S. (2001). Occupational Therapy in preschool and childcare settings. In J. C. O'Brien \& H. Kuhaneck. Case-Smith's Occupational Therapy for Children (pp. 731-755). Missouri: Mosby.

Graham, N., Truman, J., \& Heather, H. (2014). An exploratory study: expanding the concept of play for children with severe cerebral palsy. British Journal of Occupational Therapy, 77(7), 358-365. http://dx.doi.org/10.4276/030802214X14044755581781.

Hemmingsson, H., Borell, L., \& Gustavsson, A. (2003). Participation in school: school assistants creating opportunities and obstacles for pupils with disabilities. OTJR: Occup Particip Health, 23(3), 88-98. http://dx.doi.org/10.1177/153944920302300302.

Hobson, J. A., Hobson, R. P., Malik, S., Bargiota, K., \& Caló, S. (2013). The relation between social engagement and pretend play in autism. British Journal of Developmental Psychology, 31(1), 114-127. http://dx.doi.org/10.1111/j.2044-835X.2012.02083.x.

Joaquim, R. H. V. T., \& Rizzo, I. C. (2018). Crianças na creche: o cuidado e a educação. In C. M. S. Martinez \& C. R. Silva (Orgs.), Redes de cooperação em creches: sete histórias sobre a integralidade do cuidado na infância e intersetorialidade em ação (pp. 93-103). São Carlos: EdUFSCar. 
Jurdi, A. P. S., Teixeira, P. A., \& Sá, C. S. C. (2017). Vulnerabilidade sócio ambiental e o cuidado na primeira infância: o olhar da terapia ocupacional para o trabalho em creche. Revista de Terapia Ocupacional da Universidade de São Paulo, 28(3), 281-289. http://dx.doi.org/10.11606/issn.22386149.v28i3p281-289.

Klinger, E. F., \& Souza, A. P. R. (2015). Análise clínica do brincar de crianças do espectro autista. Distúrbios da Comunicação, 27(1), 15-25.

Lane, S. J. (2012). Occupation and Participation: the heart of pediatric occupational therapy: Kids want to do things. In S. J. Lane, \& A. C. Bundy. Kids can be kids: a childhood occupations approach (pp. 3-9). Philadelphia: F.A. Davis Company.

Law, M., Petrenchik, T., Ziviani, Z., \& King, G. (2006). Participation of children in school and community. In S. Rodger \& J. Ziviani (Eds.), Occupational Therapy with children: understanding children's occupations and enabling participation (pp. 67-90). Malden: Blackwell Publishing.

Lynch, H., \& Moore, A. (2016). Play as an occupation in occupational therapy. British Journal of Occupational Therapy, 79(9), 519-520. http://dx.doi.org/10.1177/0308022616664540.

Mandich, A., \& Rodger, S. (2006). Doing, being and becoming: their importance for children. In S. Rodger \& J. Ziviani (Eds.), Occupational Therapy with children: understanding children's occupations and enabling participation (pp. 115-135). Malden: Blackwell Publishing.

Martinez, C. M. S., Fontaine, A. M. G., Santos, J. F. L., Marini, B. P. R., \& Manzini, M. G. (2016). Redes de colaboração e intersetorialidade nas creches públicas do estado de São Paulo. Cadernos de Terapia Ocupacional da UFSCar, 24(4), 673-680. http://dx.doi.org/10.4322/0104-4931.ctoAO0717.

Memari, A. H., Panahi, N., Ranjbar, E., Moshayedi, P., Shafiei, M., Kordi, R., \& Ziaee, V. (2015). Children with autism spectrum disorder and patterns of participation in daily physical and play activities. Neurology Research International, 2015, 1-7. http://dx.doi.org/10.1155/2015/531906.

Moreira, D. S., Vitta, A., Penitente, L. A. A., \& Vitta, F. C. F. (2014). Influência de procedimentos educativos sobre os conceitos de berçários. Revista de Terapia Ocupacional da Universidade de São Paulo, 25(3), 217-224. http://dx.doi.org/10.11606/issn.2238-6149.v25i3p217-224.

Mulligan, S. (2012). Preschool: I'm learning now! In S. J. Lane \& A. C. Bundy. Kids can be kids: a childhood occupations approach (pp. 63-82). Philadelphia: F.A. Davis Company.

Murdock, L. C., \& Hobbs, J. Q. (2011). Picture me playing: increasing pretend play dialogue of children with autism spectrum disorders. Journal of Autism and Developmental Disorders, 41, 870-878. http://dx.doi.org/10.1007/s10803-010-1108-6.

Oliveira, J. P., \& Araujo, M. A. (2019). A participação de uma criança com Síndrome de Down em práticas pedagógicas na Educação Infantil. Revista Ibero-Americana de Estudos em Educação, 14(Esp. 1), 869-882. http://dx.doi.org/10.21723/riaee.v14iesp.1.12212.

Oliveira, P. M. R., Dutra, L. R., Melo, P. P. T., \& Rezende, M. B. (2015). Facilitadores e barreiras no processo de inclusão escolar de crianças com necessidades educativas especiais: a percepção das educadoras. Revista de Terapia Ocupacional da Universidade de São Paulo, 26(2), 186-193. http://dx.doi.org/10.11606/issn.2238-6149.v26i2p186-193.

Pelosi, M. B., \& Nunes, L. R. D. P. (2011). A ação conjunta dos profissionais da saúde e da educação na escola inclusiva. Revista de Terapia Ocupacional da Universidade de São Paulo, 22(1), 52-59. http://dx.doi.org/10.11606/issn.2238-6149.v22i1p52-59.

Pfeifer, L. I., Pacciulio, A. M., Santos, C. A., Santos, J. L., \& Stagnitti, K. E. (2011). Pretend play of children with cerebral palsy. Physical \& Occupational Therapy in Pediatrics, 31(4), 390-402. http://dx.doi.org/10.3109/01942638.2011.572149.

Pontes, T. B., Almeida, C. P., Polatajko, H. J., \& Davis, J. A. (2018). Diferenças e semelhanças nos repertórios ocupacionais de crianças brasileiras e canadenses. Journal of Occupational Science, 25(4), 530-541. http://dx.doi.org/10.1080/14427591.2018.1551049.

Rocha, A. N. D. C., \& Deliberato, D. (2012). Atuação do terapeuta ocupacional no contexto escolar: o uso da tecnologia assistiva para o aluno com paralisia cerebral na educação infantil. Revista de Terapia Ocupacional da Universidade de São Paulo, 23(3), 263-273. http://dx.doi.org/10.11606/issn.22386149.v23i3p263-273. 
Rutherford, G. S., Young, S. H., \& Sally, J. R. (2007). A longitudinal study of pretend play in autism. Journal of Autism and Developmental Disorders, 37, 1024-1039. http://dx.doi.org/10.1007/s10803-006-0240-9.

Sant'Anna, M. M. M. (2016). Formação continuada em serviço para professores da Educação Infantil sobre o brincar (Tese de doutorado). Universidade Estadual Paulista, Marília.

Shepherd, J. (2012). Self-care: a primary occupation. In S. J. Lane \& A. C. Bundy. Kids can be kids: a childhood occupations approach (pp. 125-158). Philadelphia: F.A. Davis Company.

Silva, C. C. B., Jurdi, A. P. S., \& Pontes, F. V. (2012). Transtorno do déficit de atençâo e hiperatividade: possibilidades de atuaçáo da Terapia Ocupacional em contextos educacionais. Revista de Terapia Ocupacional da Universidade de São Paulo, 23(3), 283-288. http://dx.doi.org/10.11606/issn.22386149.v23i3p283-288.

Zafani, M. D., Omote, S., \& Baleotti, L. R. (2016). Opinião de mães e professoras sobre o uso de um protocolo de observação do desempenho de crianças com deficiência física. Revista de Terapia Ocupacional da Universidade de São Paulo, 27(1), 36-41. http://dx.doi.org/10.11606/issn.22386149.v27ilp36-41.

Ziviani, J., \& Muhlenhaupt, M. (2006). Student participation in the classroom. In S. Rodger \& J. Ziviani (Eds.), Occupational Therapy with children: understanding children's occupations and enabling participation (pp. 241-260). Malden: Blackwell Publishing.

\section{Contribuiçáo dos Autores}

Débora Ribeiro da Silva Campos Folha: Concepção do projeto, coleta de dados, concepção do texto, sistematização e categorizaçáo dos dados, elaboraçáo das análises, organização das fontes, redação do texto. Patrícia Carla de Souza Della Barba: Idealização e orientação da pesquisa, elaboração das análises, revisão do texto. Todos os autores aprovaram a versão final do texto.

\section{Fonte de Financiamento}

Universidade do Estado do Pará (UEPA).

\section{Autora para correspondência}

Débora Ribeiro da Silva Campos Folha

e-mail: debora.folha@uepa.br

\section{Editora de seçáo}

Profa. Dra. Tatiana Pontes 